\title{
Comparing Two Pre-Service Learning Scenario Formats: Web-Conference \& In-Person
}

\author{
Rebecca R. Robichaux-Davis' ${ }^{\text {, Anthony J. Guarino² }}$ \\ ${ }^{1}$ Department of Curriculum, Instruction, and Special Education, Mississippi State University, Starkville, USA \\ ${ }^{2}$ Department of Biostatistics, MGH Institute of Health Profession, Boston, USA \\ Email: rrr102@msstate.edu, ajguarino@mgh.harvard.edu
}

Received 20 May 2014; revised 23 June 2014; accepted 3 July 2014

Copyright (C) 2014 by authors and Scientific Research Publishing Inc.

This work is licensed under the Creative Commons Attribution International License (CC BY).

http://creativecommons.org/licenses/by/4.0/

(c) (i) Open Access

\begin{abstract}
The primary objective of this study was to compare student satisfaction on two different teaching formats, in-person instruction (IPI) and web-conference instruction (WCI). Participants were 42 pre-service teachers who were completing their service learning requirements. Students were enrolled as elementary education majors in a teacher education undergraduate program in the southeast United States. A seven-item course evaluation survey was developed to assess such students' areas as understanding the learning objectives, comfort level of the learning environment, instructor communication barriers, and willingness for future participation. Findings from this study indicated that web-conference instruction provided equivalent levels of students' 1) understanding the learning objectives, 2) comfort level of the learning environment, and 3) willingness for future participation as the in-person format.
\end{abstract}

\section{Keywords}

Simulation Instruction, Service Learning, Student Satisfaction

\section{Introduction}

Service learning initiatives are increasingly popular among pre-service teacher education programs as a way to move students from theory to practice (Bringle \& Hatcher, 1996; Furco, 2002). The traditional in-person instruction (IPI) of service learning often exacerbates the teacher's demands resulting with students becoming little more than unsupervised volunteers, which is anathema to the goals of service learning (Tabor, 2007). Web-conference instruction (WCI) has been offered as a potential remedy. A critical barrier to implementing WCI is the 
availability of qualified instructors (Curran, 2006). These teachers must often forfeit some of their professional responsibilities in order to train pre-service teachers. Permitting instructors to remotely observe and debrief sessions may create service learning instruction more convenient, thus minimizing the resource drain from teachers attempting to supervise pre-service teachers (Vaughan, 2010). However, there is a paucity of research evaluating the efficacy of WCI. The aims of this study were to assess if WCI provided equivalent levels of students' 1) understanding the learning objectives, 2) comfort level of the learning environment, and 3) willingness for future participation as the in-person format.

\section{Method}

\subsection{Participants}

Participants were 42 pre-service teachers who were completing their service learning requirements. Students were enrolled as elementary education majors in a teacher education undergraduate program in the southeast United States. Sixteen of the students were female. All participants were Caucasian. Each student received both the IPI and the WCI instruction. WCI sessions were conducted by off-site teachers who observed the service learning encounter via a web-cam and communicated via speakerphone.

\subsection{Instrumentation}

A seven-item course evaluation survey was developed to assess such students' experiences as understanding the learning objectives, comfort level of the learning environment, instructor communication barriers, and willingness for future participation (items are listed below). Participants responded to each item using a five-point Likert-type scale ranging from 1 (Strongly Disagree) to 5 (Strongly Agree).

\section{Results}

A 2 (Format: IPI or WCI) $\times 7$ (Survey Items) repeated measure analysis of variance (ANOVA) indicated a statistically significant interaction effect, $\mathrm{F}(6,15)=14.08, p<.001, \eta 2=.76$. Follow-up paired t-tests detected that although the IPI format demonstrated statistically significant higher scores on all items than the WCI format, these differences failed to achieve any practical significance. Five of the items had differences less than a single point. Six of the seven items for both formats were in the "Agree" (positive) range. The only item demonstrating a meaningful difference concerned item 6 (Communication). Participants rated communication higher in the IPI format than the WCI format with $\mathrm{M}=4.52$ (95\% CI, 4.06 - 4.99) and $\mathrm{M}=3.09$ (95\% CI, 2.6 - 3.59). Means, standard errors, and 95\% Lower Bound (LB) and Upper Bound (UB) 95\% CI are presented in Table 1.

\section{Discussion}

Findings from this study indicated that web-conference instruction provided equivalent levels of students' 1) understanding the learning objectives, 2) comfort level of the learning environment, and 3) willingness for future

Table 1. Means, standard deviations, and 95\% CI for the scale items.

\begin{tabular}{|c|c|c|c|c|c|c|c|c|}
\hline \multirow{2}{*}{ Item } & \multicolumn{4}{|c|}{ IPI } & \multicolumn{4}{|c|}{ WCI } \\
\hline & $\mathrm{M}$ & SD & LB & UB & M & SD & LB & UB \\
\hline 1 & 4.79 & .10 & 4.59 & 4.99 & 4.13 & .16 & 3.79 & 4.46 \\
\hline 2 & 4.90 & .07 & 4.74 & 5.05 & 4.00 & .11 & 3.77 & 4.23 \\
\hline 3 & 4.74 & .10 & 4.52 & 4.96 & 4.25 & .13 & 3.98 & 4.52 \\
\hline 4 & 4.47 & .18 & 4.10 & 4.85 & 3.88 & .12 & 3.62 & 4.13 \\
\hline 5 & 4.32 & .15 & 3.99 & 4.64 & 3.50 & .15 & 3.18 & 3.82 \\
\hline 6 & 4.53 & .22 & 4.06 & 4.99 & 3.10 & .24 & 2.60 & 3.60 \\
\hline 7 & 4.90 & .07 & 4.74 & 5.05 & 3.88 & .12 & 3.62 & 4.13 \\
\hline
\end{tabular}


participation as the in-person format. Students agreed that they acquired new skills and new knowledge under both formats. Additional comments supported the use of web-conferencing, with the only exception that the web interface attenuated the quality of student-faculty communication. Future investigation is needed to improve this student-teacher communication to a level comparable to the in-person format level.

\section{Survey Items}

1) I have a better understanding of the learning objectives in which I participated today.

2) I feel comfortable with today's instruction.

3) I feel I learned new knowledge in today's instruction.

4) I feel I learned new skills in today's instruction.

5) I feel I gained new insight regarding my professional role.

6) The communication between faculty and students was a barrier to understanding the case.

7) I would participate again in such a session.

\section{Acknowledgements}

The authors wish to thank Billy Akins for his assistance with this study.

\section{References}

Bringle, R. G., \& Hatcher, J. A. (1996). Implementing Service-Learning in Higher Education. Journal of Higher Education, 67, 221-239. http://dx.doi.org/10.2307/2943981

Curran, V. R. (2006). Tele-Education. Journal of Telemedicine and Telecare, 12, 57-63. http://dx.doi.org/10.1258/135763306776084400

Furco, A. (2002). Is Service-Learning Really Better than Community Service? In A. Furco, \& S. H. Billig (Eds.), ServiceLearning: The Essence of Pedagogy (p. 25). Greenwich, CT: Information Age Publishing.

Tabor, S. W. (2007). Narrowing the Distance: Implementing a Hybrid Learning Model. Quarterly Review of Distance Education (IAP), 8, 48-49.

Vaughan, N. D. (2010). Blended Learning. In M. F. Cleveland-Innes, \& D. R. Garrison (Eds.), An Introduction to Distance Education: Understanding Teaching and Learning in a New Era (p. 165). London: Taylor \& Francis. 
Scientific Research Publishing (SCIRP) is one of the largest Open Access journal publishers. It is currently publishing more than 200 open access, online, peer-reviewed journals covering a wide range of academic disciplines. SCIRP serves the worldwide academic communities and contributes to the progress and application of science with its publication.

Other selected journals from SCIRP are listed as below. Submit your manuscript to us via either submit@scirp.org or Online Submission Portal.
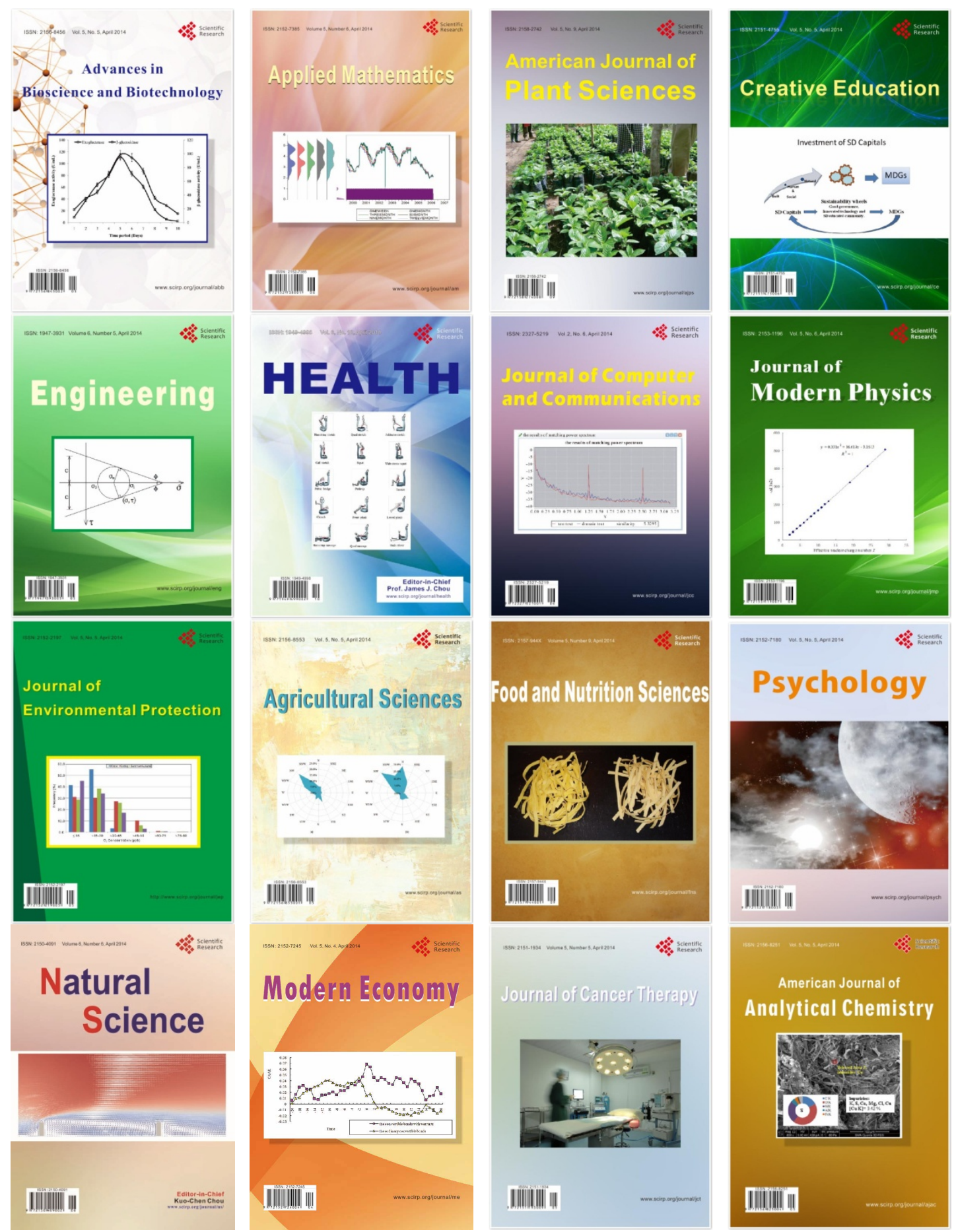